Endogenous Technol ogi cal Change, I ncome Di st $r$ i but i on, and Unempl oyment wi th I nter-Cl ass Conf I i ct

\begin{tabular}{|l|l|}
\hline 著者 & SASAK H r oaki \\
\hline j our nal or & Di scussi on Paper s ( Tohoku Economics Research \\
publ i cat i on t i t l e & Group) \\
\hline year & 2009-06 \\
\hline URL & ht t p: //hdl . handl e. net /10097/55395 \\
\hline
\end{tabular}




\section{$\mathbb{T} \mathbb{E} \mathbb{R} \mathbb{G}$}

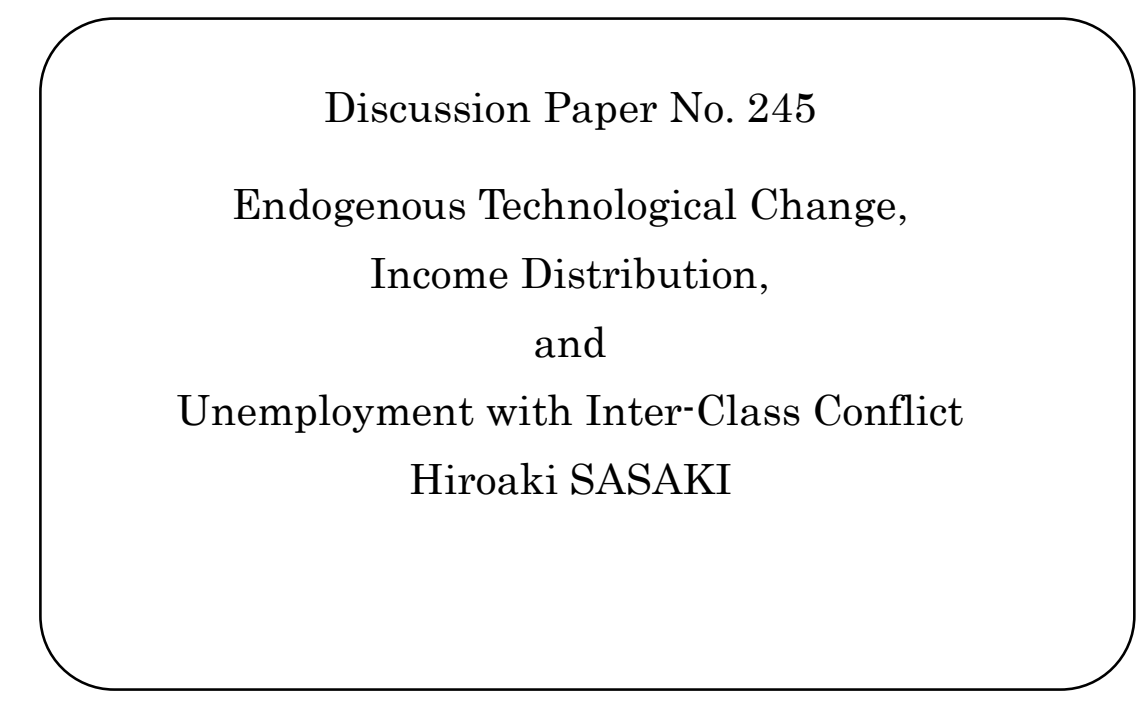

TOHOKU ECONOMICS RESEARCH GROUP

GRADUATE SCHOOL OF ECONOMICS AND MANAGEMENT TOHOKU UNIVERSITY

KAWAUCHI, AOBA-KU, SENDAI, 980-8576 JAPAN 
Discussion Paper No. 245

Endogenous Technological Change, Income Distribution, and Unemployment with Inter-Class Conflict

Hiroaki SASAKI

June 2009 


\title{
Endogenous Technological Change, Income Distribution, and Unemployment with Inter-Class Conflict
}

\author{
Hiroaki SASAKI*
}

June 2009

\begin{abstract}
This paper presents a Kaleckian model of growth that incorporates endogenous technological change. The model endogenously determines the rate of capacity utilization, the rate of economic growth, income distribution, and the employment rate besides technological change. The paper shows that whether or not an increase in the relative bargaining power of workers raises the long-run equilibrium unemployment rate depends on which regime is realized in the long-run equilibrium. If, for example, the long-run equilibrium corresponds to the wage-led growth regime, a rise in the relative bargaining power of workers leads to a decline in the unemployment rate. This result is never obtained from the mainstream NAIRU model.
\end{abstract}

Keywords: Kaleckian model; endogenous technological change; unemployment; interclass conflict

JEL Classification: E12; E24; E25

${ }^{*}$ Graduate School of Economics and Management, Tohoku University, 27-1 Kawauchi, Aoba-ku, Sendai 980-8576, Japan. E-mail: hsasaki@ hotmail.co.jp 


\section{Introduction}

This paper presents a Kaleckian model of growth that incorporates endogenous technological change and investigates the rate of economic growth, income distribution, and the employment rate. ${ }^{1}$ Although a large number of attempts to endogenize technical progress have been made in mainstream growth theory, relatively less attention has been paid in the postKeynesian tradition. In mainstream growth models, much emphasis is placed on technical progress as an engine of growth because supply-side factors determine economic growth. In contrast, because demand-side factors decide economic growth in post-Keynesian growth models, supply-side factors have not been considered so much. This is not to say that there have been no attempts to endogenize technical progress in the Kaleckian model. You (1994) introduces into a Kaleckian model a technical progress such that the growth rate of the capital-labor ratio depends on the rate of capital accumulation. In Cassetti (2003), induced technical progress known as the Kaldor-Verdoorn law (Verdoorn, 1949; Kaldor, 1966) is incorporated into a Kaleckian growth model. Stockhammer and Onaran (2004) also use the Kaldor-Verdoorn law to build a model based on Marglin and Bhaduri's (1990) work, and they empirically test the model for the US, UK, and France by means of a structural VAR analysis. Lima (2004) develops a Kaleckian model in which endogenous technological innovation plays a significant role. In Lima's model, the rate of labor-saving technological innovation depends non-linearly on the wage share, which can generate limit cycles as to the wage share and the capital-effective labor ratio.

To endogenize technological change, this paper adopts a technique such that the growth rate of labor productivity depends positively on the rate of employment. This formulation is proposed by Dutt (2006) and Bhaduri (2006). ${ }^{2}$ According to Dutt (2006), this view of technological change differs from the mainstream endogenous growth theory in that it draws attention on the demand side of the economy: technological change occurs in response to labor shortage caused by the growth of employment rather than supply side which focuses on the research and development process. Bhaduri (2006) states that this captures a view that technological change is driven by inter-class conflict over income distribution between workers and capitalists. Bhaduri's (2006) model is not a Kaleckian one because income distribution is not determined by mark-up pricing. However, it bears similarity to the Kaleckian model in that effective demand plays a crucial role in determining output. In contrast, Dutt's (2006) model can be said to be Kaleckian, but it does not deal with such issues as income

\footnotetext{
${ }^{1}$ See Kalecki $(1954,1971)$ for his economic theory. For the fundamental Kaleckian model, see Rowthorn (1981), Lavoie (1992), Taylor (2004), and Lavoie (2006).

${ }^{2}$ Bhaduri (2006) proposes two specifications. One is what we employ in this paper, and the other is that the growth rate of labor productivity is adjusted through the gap between the growth rates of real wage and labor productivity.
} 
distribution and inflation because its purpose is to present a simple growth model that integrates the roles of aggregate demand and aggregate supply.

Our specification of endogenous technological change has the following theoretical implication. Conventional Kaleckian growth models assume that labor supply is unlimited and that firms employ as many workers as they desire at given wages. If, however, the labor supply grows at an exogenously given rate, there is no guarantee that the endogenously determined growth rate of employment is equal to the growth rate of labor supply. Thus, if the growth of labor supply exceeds that of labor demand in the steady state, then the rate of unemployment will keep on rising, but this is unrealistic. ${ }^{3}$ In contrast, the steady state unemployment rate in our model remains constant because the two growth rates coincide in the long run. Therefore, our model overcomes the weakness of existing Kaleckian models.

It is true that our paper is not an initial attempt to consider the determination of the employment rate explicitly in the Kaleckian model. Stockhammer (2004) presents an augmented Kaleckian model that incorporates equations which determine employment and income distribution, and investigates the NAIRU (non-accelerating inflation rate of unemployment). ${ }^{4}$ However, our model differs considerably from Stockhammer's model in the determination of employment and income distribution. Stockhammer (2004) uses an employment determination equation such that a change in the unemployment rate is given by the difference between the growth rate of exogenous labor supply and the rate of capital accumulation, and an income distribution determination equation such that the profit share depends on the unemployment rate. On the other hand, we use an employment determination equation such that the growth rate of labor productivity depends positively on the employment rate, and an income distribution equation which results from the theory of conflicting-claims inflation. Furthermore, our model is different from Stockhammer's model in that what variables are used in the investment function and whether technological progress is exogenous or endogenous. With these differences we obtain results different from Stockhammer's results. In Stockhammer's model, the rate of capital accumulation (and accordingly the rate of capacity utilization) and the profit share are adjusted in the short run while the unemployment rate is adjusted in the long run. However, employment (and accordingly unemployment) necessarily changes with changes in the rate of capacity utilization. Hence, it is reasonable to assume that these three variables - the rate of capacity utilization, the profit share, and the employment rate—are adjusted at the same time. Therefore, we simultaneously analyze the adjustment process of these three variables.

The basic framework of our model is based on a series of Mario Cassetti's studies (Cas-

\footnotetext{
${ }^{3}$ Cassetti (2002) also sees it as a problem that the long-run rate of employment in the conventional Kaleckian model is not constant.

${ }^{4}$ For the NAIRU, see also Stockhammer (2008).
} 
setti, 2002; 2003; 2006). In standard Kaleckian models, the level of money wage and markup are fixed and given exogenously, so that the price level is constant. Cassetti (2002, 2003, 2006) combine a Kaleckian growth model and the theory of conflicting-claims inflation, in which the rate of inflation is determined by negotiations between workers and capitalists (Rowthorn, 1977). ${ }^{5}$ Kaleckian models with the theory of conflicting-claims inflation consider the effect of class conflict between workers and capitalist on income distribution, but do not consider its effect on employment. It is interesting to investigate how changes in the bargaining power of both classes affect employment.

The remainder of the paper is organized as follows. Section 2 presents the basic framework of our model. Section 3 analyzes the existence and the stability of the long-run equilibrium. Section 4 presents numerical examples to show that the long-run equilibrium actually exists under plausible parameter settings and that each variable in the model converges to its long-run equilibrium value from an arbitrary initial value. Section 5 offers results of comparative statics analysis in the long-run equilibrium. Section 6 concludes the paper.

\section{Basic framework of the model}

\subsection{Adjustment in the rate of capital accumulation}

Consider an economy in which there are two social classes, workers and capitalists. Suppose that workers consume all their wages and capitalists save a constant fraction $s$ of their profits. Let $r$ and $K$ be the rate of profit and the capital stock, respectively. Then, the real saving is given by $S=s r K$, so that the ratio of the real saving to the capital stock, $g_{s}=S / K$, leads to

$$
g_{s}=s r, \quad 0<s \leq 1
$$

We ignore capital depreciation for simplicity.

Suppose that firms operate with the following fixed coefficient production function:

$$
Y=\min \{a E,(u / k) K\},
$$

where $Y$ is real output, $E$ employment, and $a=Y / E$ the level of labor productivity. ${ }^{6}$ The rate of capacity utilization is defined as $u=Y / Y^{*}$, where $Y^{*}$ is the potential output. Let us define the ratio of the capital stock to the potential output as $k=K / Y^{*}$ and suppose that $k$ is

\footnotetext{
${ }^{5}$ Lima (2004), mentioned above, is also an attempt to integrate the theory of conflicting-claims inflation with a Kaleckian growth model.

${ }^{6}$ Given the Leontief production function, a profit maximizing firm will choose employment and capacity utilization in such a way that $a E=(u / k) K$, from which it follows that $a=Y / E$.
} 
constant, that is, both $K$ and $Y^{*}$ grow at the same rate. ${ }^{7}$ To simplify the analysis we assume $k=1$. Then, we obtain $u=Y / K$. Note that the relationship among the profit rate, the profit share $(m)$, and the rate of capacity utilization is given by $r=m u$ and the relationship among the rate of capacity utilization, the rate of capital accumulation, and the profit share is given by $u=g /(s m)$.

Following the argument of Marglin and Bhaduri (1990), we specify the ratio of the real investment to the capital stock, $g_{d}=I / K$, as follows:

$$
g_{d}=A m^{\phi} u^{\gamma}, \quad A>0,0<\phi<1,0<\gamma<1,
$$

where $A$ denotes a constant, $\phi$ the elasticity of the investment rate with respect to the profit share, $\gamma$ the elasticity of the investment rate with respect to the rate of capacity utilization. Equation (3) means that the desired investment rate of firms is an increasing function both in the profit share and in the rate of capacity utilization. In conventional Kaleckian models, the investment function is assumed to depend positively on the rate of profit and the rate of capacity utilization. Marglin and Bhaduri (1990), in contrast, argue that not the rate of profit but the profit share should be a variable in the investment function. The reason for this is as follows. The rate of profit is equal to the product of the profit share and the rate of capacity utilization divided by the capital output ratio at full capacity, that is, $r=m u / k$. Thus, it is plausible that a combination of high capacity utilization and a low profit share and a combination of low capacity utilization and a high profit share will produce different levels of investment even when the rate of profit is held constant at a given level. ${ }^{8}$ Our specification of the investment function is based on Blecker (2002). ${ }^{9}$ Since the investment function is not a linear but a Cobb-Douglas form, as will be shown later, different regimes can be produced according to the sizes of $\phi$ and $\gamma$.

An equation of motion for the rate of capacity utilization can be formulated by

$$
\dot{u}=\alpha\left(g_{d}-g_{s}\right), \quad \alpha>0,
$$

where $\alpha$ is the speed of adjustment. Equation (4) represents quantity adjustment by the rate

\footnotetext{
${ }^{7}$ Foley and Michl (1999) emphasize that, in capitalist economies, a combination of growing labor productivity and declining capital productivity (i.e., a rise in $k$ in our model) is the typical pattern of technological change. They accordingly term the pattern Marx-biased technical change. When an economy experiences Marx-biased technical change, the rate of profit will decline as long as the profit share remains constant. In our model, such a biased technical change is not taken into consideration.

${ }^{8}$ For the details of the argument, see also Bhaduri and Marglin (1990).

${ }^{9}$ If $\phi>1$ in this specification, we have the exhilarationist regime in which an increase in the profit share leads to a rise in the rate of capacity utilization. However, $\phi>1$, as Blecker (2002) points out, is an extreme case. Hence, we assume $0<\phi<1$ in the following analysis.
} 
of capacity utilization in the goods market: excess demand $\left(g_{d}>g_{s}\right)$ leads to a rise in the rate of capacity utilization whereas excess supply $\left(g_{d}<g_{s}\right)$ leads to a decline in the rate of capacity utilization.

Substituting equations (1) and (3) into equation (4), we finally obtain the dynamics of $u$ as follows:

$$
\dot{u}=\alpha\left(A m^{\phi} u^{\gamma}-s m u\right) .
$$

\subsection{Adjustment in the profit share}

In the Kaleckian tradition, firms operate with excess capacity in oligopolistic goods markets and set their prices $p$ with a mark-up $\mu$ on unit labor costs:

$$
p=(1+\mu) \frac{w}{a}
$$

where $w$ is the money wage rate. It should be noted that $m=\mu /(1+\mu)$, that is, there exists a one-to-one relationship between the mark-up and the profit share, ${ }^{10}$ so that $m$ and $\mu$ change in the same direction. Therefore, we can rewrite equation (6) as follows:

$$
p=\left(\frac{1}{1-m}\right) \frac{w}{a}
$$

Differentiating both sides of equation (7) with respect to time yields:

$$
\frac{\dot{m}}{1-m}=\frac{\dot{p}}{p}-\frac{\dot{w}}{w}+\frac{\dot{a}}{a}
$$

To know the dynamics of $m$ we have to specify the rates of change of $p, w$, and $a$.

We specify the dynamics of the money wage and price by using the theory of conflictingclaims inflation. First, suppose that the growth rate of the money wage which workers manage to negotiate depends on the discrepancy between their target real wage rate and the actual real wage rate. Given the labor productivity, to determine the real wage means to determine the wage share. Therefore, setting the target real wage rate is equivalent to setting the target profit share. Second, suppose that firms set their price to close the gap between their target mark-up and the actual mark-up. The target mark-up corresponds to the target

\footnotetext{
${ }^{10}$ The relationship between $m$ and $\mu$ is given as follows:

$$
m=1-\frac{w E}{p Y}=1-\frac{w}{p} \frac{1}{a}=1-\frac{1}{1+\mu}=\frac{\mu}{1+\mu} .
$$
}


profit share because, as stated above, the mark-up bears a one-to-one relation to the profit share. From these the dynamics of the money wage and price can be described, respectively, as follows:

$$
\begin{aligned}
& \frac{\dot{w}}{w}=\theta_{w}\left(m-m_{w}\right), \quad \theta_{w}>0,0<m_{w}<1, \\
& \frac{\dot{p}}{p}=\theta_{f}\left(m_{f}-m\right), \quad \theta_{f}>0,0<m_{f}<1,
\end{aligned}
$$

where $\theta_{w}$ and $\theta_{f}$ are the speed of adjustment, $m_{w}$ is the target profit share set by workers, and $m_{f}$ is the profit share set by firms.

We can interpret $\theta_{w}$ and $\theta_{f}$ as the bargaining power of workers and that of firms, respectively. ${ }^{11}$ We suppose $\theta_{f}+\theta_{w}=1$ and define $\theta_{f} \equiv \theta$ because bargaining power is a relative concept. Then, we obtain $\theta_{w}=1-\theta$, where $0<\theta<1 .{ }^{12}$ We can take an increase in the unionization rate as a factor for raising the bargaining power of workers (i.e., a decrease in $\theta$ ), and an increase in the market power of oligopolistic firms as a factor for raising the bargaining power of firms (i.e., an increase in $\theta$ ).

Notice the difference between $\theta$, and $m_{f}$ and $m_{w}$. The parameter $\theta$ represents the relative bargaining power of firms (workers) and reflects the power to realize their demands. In contrast, $m_{f}$ and $m_{w}$ reflect their demands in the bargaining. To what extent their demands can be realized depends on $\theta$.

Substituting equations (9) and (10) into equation (8), we obtain an equation of motion for the profit share:

$$
\dot{m}=-(1-m)\left[m-\theta m_{f}-(1-\theta) m_{w}-g_{a}\right]
$$

where $g_{a}=\dot{a} / a$ is the growth rate of labor productivity.

\subsection{Adjustment in the growth rate of labor productivity}

We now turn to the specification of endogenous technological change. Following Bhaduri (2006) and Dutt (2006), we describe the growth rate of labor productivity as follows:

$$
g_{a}=\lambda e^{\beta}, \quad \lambda>0, \beta>0,
$$

\footnotetext{
${ }^{11}$ This interpretation is also adopted in Lavoie (1992, p. 393), Cassetti (2002, p. 192), and Cassetti (2003, p. 453).

${ }^{12}$ The constraint $0<\theta_{w}, \theta_{f}<1$ is also adopted by Dutt and Amadeo (1993), who, however, do not assume $\theta_{f}+\theta_{w}=1$. Even if we only impose $0<\theta_{w}, \theta_{f}<1$ and do not impose $\theta_{f}+\theta_{w}=1$, we obtain similar results.
} 
where $e$ is the employment rate, which is defined as $e=E / N$ with $N$ being the exogenous labor supply, $\lambda$ is a constant, and $\beta$ is the elasticity of the growth rate of labor productivity with respect to the employment rate.

Equation (12) shows that the growth rate of labor productivity is an increasing function of the employment rate. In general, the natural rate of growth is defined as a sum of the growth rate of labor productivity and that of labor supply. Although the growth rate of labor supply in our model is exogenously given, the growth rate of labor productivity is endogenously determined. Under our specification, therefore, the natural rate of growth increases while business is good (i.e., a high employment rate) and it decreases while business is bad (i.e., a low employment rate). The assumption that the natural rate of growth is endogenously determined is consistent with empirical studies of León-Ledesma and Thirlwall (2002), Libânio (2009), and Vogel (2009).

Using equation (12), we can show that in the long-run equilibrium the growth rate of output per capita $(Y / N)$ coincides with that of labor productivity $(Y / E)$. In this respect Sedgley and Elmslie (2004) empirically show the cointegration between the log of output per capita and the log of labor productivity. ${ }^{13}$ This evidence suggests that these two variables move together in the long run.

From equation (12), the rate of change of $g_{a}$ is given by

$$
\frac{\dot{g}_{a}}{g_{a}}=\beta \frac{\dot{e}}{e}
$$

From equation (2) the employment is $E=u K / a$, and the employment rate is $e=u K /(a N)$, so that the rate of change of the employment rate leads to

$$
\frac{\dot{e}}{e}=\frac{\dot{u}}{u}+g-g_{a}-n
$$

where $n$ is the growth rate of $N$ and given exogenously. We should pay attention to the rate of capital accumulation $g$ in equation (14). In our model there are two kinds of rates of capital accumulation, that is, $g_{d}$ and $g_{s}$. We have $g=g_{d}=g_{s}$ in equilibrium. However, we have $g_{d} \neq g_{s}$ out of equilibrium. Therefore, we face the problem of which rates of capital accumulation we should adopt in equation (14). Because investment determines saving in

\footnotetext{
${ }^{13}$ Their original purpose is to empirically test which model is more valid, the classical conventional wage share model proposed by Foley and Michl (1999) or the classical full employment model proposed by Pasinetti (1974). The growth rate of output per capita and that of labor productivity do not coincide in the classical conventional wage share model, whereas the two growth rates coincide in the classical full employment model. For this reason we can know which model is more valid by examining the long-run relationship between the two variables.
} 
the model, we should adopt $g_{d}$ as the actual rate of capital accumulation. ${ }^{14}$

Substituting equations (3) and (5) into equation (14), and the resultant expression into equation (13), we obtain the dynamics of $g_{a}::^{15}$

$$
\dot{g}_{a}=\beta g_{a}\left[\alpha\left(A m^{\phi} u^{\gamma-1}-s m\right)+A m^{\phi} u^{\gamma}-g_{a}-n\right] .
$$

\section{Existence and stability of the long-run equilibrium}

From equations (5), (11), and (15), our model consists of the following system of differential equations:

$$
\begin{aligned}
\dot{u} & =\alpha\left(A m^{\phi} u^{\gamma}-s m u\right), \\
\dot{m} & =-(1-m)\left[m-\theta m_{f}-(1-\theta) m_{w}-g_{a}\right], \\
\dot{g}_{a} & =\beta g_{a}\left[\alpha\left(A m^{\phi} u^{\gamma-1}-s m\right)+A m^{\phi} u^{\gamma}-g_{a}-n\right] .
\end{aligned}
$$

\subsection{Existence of the long-run equilibrium}

Long-run equilibrium is a situation in which $\dot{u}=\dot{m}=\dot{g}_{a}=0$, from which we have the following three equations in order:

$$
\begin{aligned}
& A m^{\phi} u^{\gamma}=s m u, \\
& m=\theta m_{f}+(1-\theta) m_{w}+g_{a}, \\
& A m^{\phi} u^{\gamma}=g_{a}+n .
\end{aligned}
$$

From equation (19) we have

$$
u=A^{\frac{1}{1-\gamma}} S^{-\frac{1}{1-\gamma}} m^{\frac{\phi-1}{1-\gamma}}
$$

Substituting $g_{a}=s m u-n$ from equations (19) and (21) into equation (20), and substituting equation (22) into the resultant expression, we obtain

$$
A^{\frac{1}{1-\gamma}} S^{-\frac{\gamma}{1-\gamma}} m^{\frac{\phi-\gamma}{1-\gamma}}-m+\theta m_{f}+(1-\theta) m_{w}-n=0
$$

This equation determines $m^{*}$ (hereafter, equilibrium values are denoted with “*”). Using $m^{*}$, we can find $u^{*}$ and $g_{a}^{*}$.

\footnotetext{
${ }^{14}$ See also Marglin (1984, pp. 85-88) in this respect.

${ }^{15}$ We can use an equation of motion for $e$ instead of the one for $g_{a}$ because $e$ is related to $g_{a}$ through equation (12). Naturally, we have the same results.
} 
Let us explain the determination of $m^{*}$. We rewrite equation (23) as follows:

$$
A^{\frac{1}{1-\gamma}} S^{-\frac{\gamma}{1-\gamma}} m^{\frac{\phi-\gamma}{1-\gamma}}+B=m+n
$$

where $B \equiv \theta m_{f}+(1-\theta) m_{w}$. Each side of equation (24) is a function of $m$, so that we can write each side as follows:

$$
\begin{aligned}
& \mathrm{LHS} \equiv F_{m}(m)=A^{\frac{1}{1-\gamma}} S^{-\frac{\gamma}{1-\gamma}} m^{\frac{\phi-\gamma}{1-\gamma}}+B, \\
& \mathrm{RHS} \equiv G_{m}(m)=m+n .
\end{aligned}
$$

The intersection of these curves determines $m^{*} . F_{m}(m)$ can be upward sloping or downward sloping depending on the sizes of $\phi$ and $\gamma . G_{m}(m)$ is a straight line such that the slope and the intercept are unity and $n$, respectively. From this we have Figures 1 and 2 . Both figures are drawn with the condition that $0<m^{*}<1$.

[Figures 1 and 2 to be inserted here]

To obtain these figures we need the constraints $B>n$ and $G_{m}(1)>F_{m}(1)$. Similarly, we can find the constraints under which economically meaningful values for $u^{*}$ and $g_{a}^{*}$ are obtained. ${ }^{16}$ These constrains are summarized as follows:

$$
\begin{aligned}
m^{*} \in(0,1) & \Longrightarrow \mathrm{C} 1: B-n>0 \text { and } \mathrm{C} 2: 1+n-B-A^{\frac{1}{1-\gamma}} s^{-\frac{\gamma}{1-\gamma}}>0, \\
u^{*} \in(0,1) & \Longrightarrow \mathrm{C} 3: s(1-s)^{\phi-1}-A(B-n)^{\phi-1}>0, \\
g_{a}^{*}>0 & \Longrightarrow \mathrm{C} 4: A^{\frac{1}{1-\gamma}} s^{-\frac{\gamma}{1-\gamma}} B^{\frac{\phi-\gamma}{1-\gamma}}-n>0 .
\end{aligned}
$$

The intersection of the conditions $\mathrm{C} 1-\mathrm{C} 4$ is the necessary and sufficient condition for the long-run equilibrium values to be economically meaningful. Although it is difficult to obtain the intersection, numerical examples of parameters used in simulation below satisfy these conditions.

\subsection{Local stability of the long-run equilibrium}

To analyze the local stability of the long-run equilibrium we linearize the system of differential equations (16), (17), and (18) around the equilibrium.

\footnotetext{
${ }^{16}$ See Appendix 1 for $u^{*}$ and $g_{a}^{*}$.
} 


$$
\left(\begin{array}{c}
\dot{u} \\
\dot{m} \\
\dot{g}_{a}
\end{array}\right)=\left(\begin{array}{ccc}
J_{11} & J_{12} & 0 \\
0 & J_{22} & J_{23} \\
J_{31} & J_{32} & J_{33}
\end{array}\right)\left(\begin{array}{c}
u-u^{*} \\
m-m^{*} \\
g_{a}-g_{a}^{*}
\end{array}\right),
$$

where the elements of the Jacobian matrix $\mathbf{J}$ are given by

$$
\begin{aligned}
J_{11} & \equiv \frac{\partial \dot{u}}{\partial u}=-\alpha \operatorname{sm}(1-\gamma)<0, \\
J_{12} & \equiv \frac{\partial \dot{u}}{\partial m}=-\alpha \operatorname{su}(1-\phi)<0, \\
J_{22} & \equiv \frac{\partial \dot{m}}{\partial m}=-(1-m)<0, \\
J_{23} & \equiv \frac{\partial \dot{m}}{\partial g_{a}}=1-m>0, \\
J_{31} & \equiv \frac{\partial \dot{g}_{a}}{\partial u}=\frac{\beta s m g_{a}}{u}[\alpha(\gamma-1)+\gamma u] \gtrless 0, \\
J_{32} & \equiv \frac{\partial \dot{g}_{a}}{\partial m}=\beta s g_{a}[\alpha(\phi-1)+\phi u] \gtrless 0, \\
J_{33} & \equiv \frac{\partial \dot{g}_{a}}{\partial g_{a}}=-\beta g_{a}<0 .
\end{aligned}
$$

All elements are evaluated at the long-run equilibrium, though we omit "*" to avoid troublesome notations. $J_{31}$ and $J_{32}$ can be negative when the speed of adjustment $\alpha$ is large.

Let us explain the Jacobian matrix. The diagonal elements $J_{11}, J_{22}$, and $J_{33}$ represent the own effects of endogenous variables on themselves. They are negative, which implies that when a variable deviates from its long-run equilibrium value, it returns to the equilibrium value. This negative feedback has a stabilizing effect. However, a change in one variable affects other variables, whose effects in turn rebound on the variable in question. We take the rate of utilization for example. $J_{31}$ shows that a rise in the rate of utilization causes an increase or a decrease in the growth rate of labor productivity. If $g_{a}$ increases, then from $J_{23}$ it induces a rise in the profit share. From $J_{12}$ this rise in the profit share lowers the rate of capacity utilization. To sum up, this route has negative feedback, leading to stability. In contrast, if $g_{a}$ decreases in $J_{31}$, then from $J_{23}$ it induces a fall in the profit share, which raises the rate of capacity utilization from $J_{12}$. This route has positive feedback, leading to instability.

To examine the local stability of the long-run equilibrium, we have to know the properties of the characteristic roots of the Jacobian matrix. The characteristic equation of the 
Jacobian matrix is given by

$$
q^{3}+b_{1} q^{2}+b_{2} q+b_{3}=0
$$

where $q$ denotes a characteristic root. Each coefficient of equation (35) is expressed by

$$
\begin{aligned}
b_{1}= & -\operatorname{tr} \mathbf{J}=\alpha s m(1-\gamma)+(1-m)+\beta g_{a}>0, \\
b_{2}= & J_{22} J_{33}-J_{23} J_{32}+J_{11}\left(J_{22}+J_{33}\right) \\
= & \beta g_{a}\{(1-m)(1-s \phi u)+\alpha s[m(1-\gamma)+(1-m)(1-\phi)]\} \\
& +\alpha s m(1-\gamma)(1-m)>0, \\
b_{3}= & -\operatorname{det} \mathbf{J}=-J_{11}\left(J_{22} J_{33}-J_{23} J_{32}\right)-J_{31} J_{12} J_{23} \\
= & \alpha \beta s m(1-m) g_{a}[(1-\gamma)(1-s \phi u)+s \gamma u(1-\phi)]>0,
\end{aligned}
$$

where $-b_{1}=\operatorname{tr} \mathbf{J}$ is the trace of $\mathbf{J}, b_{2}$ is the sum of the principal minor determinants, and $-b_{3}=\operatorname{det} \mathbf{J}$ is the determinant of $\mathbf{J}$. As shown above, all signs are positive. The necessary and sufficient condition for stability is that all characteristic roots of the Jacobian matrix have negative real parts, which, from Routh-Hurwitz conditions, is equivalent to $b_{1}>0$, $b_{2}>0, b_{3}>0$, and $b_{1} b_{2}-b_{3}>0 .{ }^{17}$ We compute $b_{1} b_{2}-b_{3}$ as follows:

$$
\begin{aligned}
b_{1} b_{2}-b_{3}= & \alpha^{2} s^{2} m(1-\gamma)\left\{\beta g_{a}[m(1-\gamma)+(1-m)(1-\phi)]+m(1-\gamma)(1-m)\right\} \\
& +\beta^{2} g_{a}^{2}\{(1-m)(1-s \phi u)+\alpha s[m(1-\gamma)+(1-m)(1-\phi)]\} \\
& +(1-m)^{2}\left[\beta g_{a}(1-s \phi u)+\alpha s m(1-\gamma)\right] \\
& +\alpha \beta s(1-m) g_{a}[2 m(1-\gamma)+(1-\phi) \underbrace{(1-m-m s u \gamma)]}_{\equiv \Theta} .
\end{aligned}
$$

The sign of $b_{1} b_{2}-b_{3}$ is indeterminate. Note, however, that in equation (39) all parts except the part defined as $\Theta$ is positive. Let us turn to $\Theta$.

$$
\Theta \equiv 1-m-m s u \gamma
$$

First, when $s, u$, and $\gamma$ are close to zero, $\Theta$ will be positive because $m s u \gamma$ in $\Theta$ will be sufficiently small. Second, when $s, u$, and $\gamma$ are close to unity, $\Theta$ approaches

$$
\Theta=1-m-m=1-2 m .
$$

From this if $m^{*} \leq 1 / 2$, that is, the equilibrium profit share is smaller than or equal to $1 / 2$,

\footnotetext{
${ }^{17}$ See Gandolfo (1996) for details.
} 
then $\Theta>0$, so that $b_{1} b_{2}-b_{3}>0$. Therefore, if $m^{*} \leq 1 / 2$, the necessary and sufficient condition for the local stability of the long-run equilibrium is satisfied. In general the profit share in the real world is considered to be smaller than $1 / 2$, and thus the condition $m^{*} \leq 1 / 2$ is plausible.

Note, however, that $m^{*} \leq 1 / 2$ is a sufficient and not a necessary condition for $b_{1} b_{2}-b_{3}>$ 0 . Moreover, note that $m^{*}$ depends on the parameters of the model. ${ }^{18}$

\section{Numerical examples}

This section presents numerical examples to show that the economically meaningful longrun equilibrium actually exists under plausible parameter settings and that each variable converges to its long-run equilibrium value from an arbitrary initial value. ${ }^{19}$ Considering the shape of the investment function, we investigate two cases in what follows: $\phi<\gamma$ (Case 1) and $\phi>\gamma($ Case 2).

To begin with, we set parameters and initial conditions common to Cases 1 and 2 as follows:

$$
\begin{aligned}
& \alpha=1, \beta=0.5, A=0.3, s=0.8, \theta=0.4, m_{f}=0.3, m_{w}=0.2, n=0.04, \\
& u(0)=0.6, m(0)=0.4, g_{a}(0)=0.15 .
\end{aligned}
$$

Next, we set the parameters of the investment function as follows:

Case $1: \phi=0.2, \gamma=0.3$,

Case $2: \phi=0.3, \gamma=0.2$.

The numerical examples above satisfy the conditions C1-C4: in Case 1, C1: $0.20>0$, $\mathrm{C} 2: 0.60>0, \mathrm{C} 3: 1.81>0, \mathrm{C} 4: 0.20>0$; and in Case 2, $\mathrm{C} 1: 0.20>0, \mathrm{C} 2: 0.57>0$, $\mathrm{C} 3: 1.54>0, \mathrm{C} 4: 0.16>0$.

Table 1 shows the equilibrium values for Cases 1 and 2. From this we see that $u^{*}, m^{*}$, and $g_{a}^{*}$ all take reasonable values.

${ }^{18}$ The condition for $m^{*} \leq 1 / 2$ is given by

$$
G_{m}(1 / 2) \geq F_{m}(1 / 2) \Longrightarrow \frac{1}{2}+n \geq A^{\frac{1}{1-\gamma}} s^{-\frac{\gamma}{1-\gamma}}\left(\frac{1}{2}\right)^{\frac{\phi-\gamma}{1-\gamma}}+B
$$

\footnotetext{
${ }^{19}$ For numerical calculations, we use Mathematica 4 of Wolfram Research Inc. A Mathematica notebook file containing the code is available from the author upon request.
} 
[Table 1 to be inserted here]

Figures 3-8 show the time path (up to $t=100$ ) of each variable. Every variable converges to its equilibrium value. In these numerical examples Cases 1 and 2 show similar dynamics.

In the example we set the speed of adjustment of the goods market, that is, $\alpha$ to 1 . If we use $\alpha$ which is larger or smaller than 1 , the speed of convergence gets faster or slower. Nonetheless, each variable converges to its long-run equilibrium value.

We set the elasticity of the growth rate of labor productivity with respect to the employment rate, that is, $\beta$ to 0.5 . As can be seen from equation (18), $\beta$ also represents the speed of adjustment of $g_{a}$. As is the case with $\alpha$, even if we use $\beta$ which is larger or smaller than 0.5 , each variable converges to its equilibrium value.

[Figures 3, 4, 5, 6, 7, and 8 to be inserted here]

\section{Comparative statics analysis}

This section investigates the effects of shifts in parameters on the long-run equilibrium. Table 2 summarizes the results of comparative statics analysis. ${ }^{20}$ These results are obtained under the assumption that the long-run equilibrium is stable. In addition, $m_{f}-m_{w}>0$ is assumed in the analysis. It is reasonable to assume that firms attempt to set $m_{f}$ as high as possible whereas workers attempt to set $m_{w}$ as low as possible. Hence, the assumption $m_{f}-m_{w}>0$ can be justified. Note, finally, that $g_{a}^{*}$ and $e^{*}$ are dealt with in the same row because these two variables move in the same direction (see equation (12)).

[Table 2 to be inserted here]

- Saving rate

An increase in the saving rate decreases the rate of capacity utilization, the profit share, and the rate of capital accumulation. This negative effect on the growth rate is known as "the paradox of thrift." An increase in the saving rate decreases the employment rate, thereby increasing the unemployment rate. In Stockhammer (2004) the long-run equilibrium rate of unemployment consists of the exogenous natural rate of growth and parameters of the investment and income distribution functions, and does not depend on the saving rate. Consequently, a change in the saving rate never affects the unemployment rate. In our model, on the other hand, $g_{a}^{*}$ and accordingly the natural rate of growth are endogenously determined, so that a change in the saving rate affects the unemployment rate.

\footnotetext{
${ }^{20}$ See Appendix 2 for details.
} 
- Labor supply growth

A rise in the growth rate of labor supply increases the rate of capacity utilization and decreases the profit share. This mechanism is as follows. A rise in $n$ creates excess supply in the labor market, thereby depressing the employment rate. Because the growth rate of labor productivity depends positively on the employment rate, the depressing effect on the employment rate also decreases the labor productivity, which also decreases the profit share from equation (20). This decrease in the profit share leads to an increase in the rate of capacity utilization through equation (22). The conventional Kaleckian model cannot investigate the effect of supply side factors on equilibrium values. In contrast, our model can investigate it.

Let us turn to the effect on the employment rate. A rise in the growth rate of labor supply decreases the equilibrium employment and thus increases the equilibrium unemployment rate. Because the relation $g_{a}^{*}=s m^{*} u^{*}-n$ holds in the long-run equilibrium, a rise in $n$ has three different effects on $g_{a}^{*}$ : it directly decreases $g_{a}^{*}$ with the coefficient of $n$ being -1 ; it indirectly decreases $g_{a}^{*}$ through $m^{*}$ with $m^{*}$ decreasing in $n$; and it indirectly increases $g_{a}^{*}$ through $u^{*}$ with $u^{*}$ increasing in $n$. In total the two negative effects outweigh the one positive effect, which leads to a decrease in $g_{a}^{*}$ and $e^{*}$ with an increase in $n$. Stockhammer (2004) also concludes that an increase in the growth rate of labor supply leads to a rise in the unemployment in the profit-led growth regime where the long-run equilibrium is stable. ${ }^{21}$

Finally, a rise in the growth rate of labor supply either increases or decreases the rate of capital accumulation depending on the sizes of the two elasticities of the investment function. To understand it we need to remind ourselves that from equation (3), $g^{*}=A\left(m^{*}\right)^{\phi}\left(u^{*}\right)^{\gamma}$ holds in the long-run equilibrium. As stated above, a rise in $n$ decreases $m^{*}$ and increases $u^{*}$. When $\phi<\gamma$, the positive effect of $u^{*}$ exceeds the negative effect of $m^{*}$, so that in total $g^{*}$ increases with a rise in $n$. When $\phi>\gamma$, the converse holds.

- Bargaining power

An increase in $\theta$, which corresponds to an increase in the relative bargaining power of firms, brings about a decrease in the rate of capacity utilization and an increase in the profit share. The effect on the employment rate is worth considering. A rise in $\theta$ either increases or decreases the employment according to the sizes of $\phi$ and $\gamma$. The employment rate decreases when $\phi<\gamma$, while it increases when $\phi>\gamma$. A rise in $\theta$ has two different effects on $g_{a}$ and $e$ : it indirectly increases $g_{a}$ and $e$ through its positive effect on $m$; and it indirectly decreases $g_{a}$ and $e$ through its negative effect on $u$. Whether or not the rise in $\theta$ leads to an increase in $g_{a}$ and $e$ depends on which effect dominates, which in turn depends on the sizes the elasticities

\footnotetext{
${ }^{21}$ Rowthorn (1999) reaches a similar conclusion by using different model, in which trade unions and firms are engaged in Nash bargaining for wages.
} 
of the investment function. When $\phi<\gamma$, the negative effect of the capacity utilization dominates the positive effect of the profit share, thereby leading to a decrease in the growth rate of labor productivity and the employment rate. When $\phi>\gamma$, in contrast, the positive effect of the profit share dominates the negative effect of the capacity utilization, thereby leading to an increase in the growth rate of labor productivity and the employment rate.

Stockhammer (2004) also investigates the relationship between bargaining power and unemployment. He concludes that in the profit-led growth regime a decrease in the bargaining power of workers leads to higher employment and lower unemployment. This result is consistent with ours. However, in the wage-led growth regime of Stockhammer's model, the long-run equilibrium is unstable, so that we cannot investigate the relationship between bargaining power and unemployment. In our model, in contrast, the-long run equilibrium of the wage-led growth regime can be stable. In this case we reach the opposite conclusion that an increase in the bargaining power of firms leads to higher employment and lower unemployment. This result is consistent with the empirical result of Storm and Naastepad (2007). Using data for 20 OECD countries during 1984-1997, they show that an increase in the bargaining power of firms due to labor market deregulation raises the unemployment rate in contrast to the view of the mainstream NAIRU model. ${ }^{22}$

\section{- Target profit share}

The effect of an increase in the target profit share $m_{w}$ or $m_{w}$ is similar to that of an increase in $\theta$ discussed above because of the structure of the model. An important issue in the Kaleckian model is that different regimes arise due to the specification of the investment function. According to Blecker's (2002) classification, the stagnationist (exhilarationist) regime is a situation where an increase in the profit share decreases (increases) the rate of capacity utilization. The wage-led (profit-led) growth regime is a situation where an increase in the profit share decreases (increases) the rate of capital accumulation. The profit share in our model is not an exogenous but an endogenous variable, and thus we cannot apply Blecker's classification to the model as it is. However, because the actual profit share $m$ is closely related to the target profit shares $m_{f}$ and $m_{w}$, these variables can be a proxy variable for the actual profit share. An increase in $m_{f}$ and $m_{w}$ leads to a decrease in the rate of capacity utilization, which corresponds to the stagnationist regime. In addition, an increase in $m_{f}$ and $m_{w}$ raises the rate of capital accumulation when $\phi>\gamma$ while it lowers the growth rate when $\phi<\gamma$ : the former case corresponds to the profit-led growth regime while the latter case corresponds to the wage-led growth regime.

- Autonomous investment

\footnotetext{
${ }^{22}$ In Storm and Naastepad (2008) similar empirical results are obtained.
} 
We can regard the parameter $A$ of the investment function as expressing a demand policy. Setterfield (2009), for instance, relates a constant term of the investment function to a fiscal policy and discusses the effectiveness of output targeting and inflation targeting. An increase in $A$ in our model raises all equilibrium values: stimulating effective demand lowers the unemployment rate even in the long run. This implication makes a marked contrast to the implication of the mainstream NAIRU theory.

\section{Concluding remarks}

This paper has developed a Kaleckian model in which the rate of technological change and the employment rate are endogenously determined. The model is based on the Kaleckian model with the theory of conflicting-claims inflation, and is extended to incorporate endogenous technological change. Our model responds to the criticism that in the usual Kaleckian model technological change is not considered and the long-run employment rate is not constant.

Using the model, we have analyzed how the relative bargaining power of workers and firms affects the long-run equilibrium rate of unemployment. The relationship between the bargaining power and the unemployment rate differs depending on the regime in which the long-run equilibrium lies. If the long-run equilibrium is characterized as the wage-led growth regime, a rise in the relative bargaining power of firms increases the unemployment rate. If, on the other hand, the long-run equilibrium is characterized as the profit-led growth regime, a rise in the relative bargaining power of workers increases the unemployment rate. The latter result is also obtained in the mainstream NAIRU model, but the former result is never obtained in the mainstream model. Note, however, that a fall in the firms' bargaining power, that is, a rise in the workers' bargaining power leads to higher employment, but it simultaneously leads to lower profit share: workers' interests interfere with firms' interests. For this reason it may be difficult to implement an economic policy intended to adjust the bargaining power of both classes. Even in this case, nonetheless, demand stimulation policy is effective. As discussed in the text, stimulation of effective demand brings about higher employment and accordingly lower unemployment. This policy implication is never obtainable from the mainstream NAIRU theory.

Our way of introduction of technological change is very simple. Rowthorn (1981) states that technical progress influences an economy in two ways. First, technical progress makes existing equipment obsolete, and thus it will affect the rate of depreciation. Second, technical progress stimulates firms that undertake innovations to invest more by bringing extra profits to them, and thus the form of investment function will be modified. In Cassetti (2003) 
these effects are taken into account, while in the present paper these issues are not dealt with for the purpose of emphasizing the role of endogenous technological change in the Kaleckian model of growth. For the same purpose target rates of workers and firms are not endogenized. It is evident that technological change influences the target rates if these are endogenized. Taking these into account will be future research.

\section{A Appendix 1}

\section{A.1 Determination of the equilibrium rate of capacity utilization}

Eliminating $m$ and $g_{a}$ from equations (19), (20), and (21), we obtain the following equation for $u$ :

$$
A(B-n)^{\phi-1} u^{\gamma-1}=s(1-s u)^{\phi-1} .
$$

Both sides are functions of $u$. Thus, we can rewrite them as follows:

$$
\begin{aligned}
\mathrm{LHS} & \equiv F_{u}(u)=A(B-n)^{\phi-1} u^{\gamma-1}, \\
\mathrm{RHS} & \equiv G_{u}(u)=s(1-s u)^{\phi-1} .
\end{aligned}
$$

The intersection of these curves determines $u^{*}$.

[Figure 9 to be inserted here]

\section{A.2 Determination of the equilibrium growth rate of labor productiv- ity}

Eliminating $u$ and $m$ from equations (19), (20), and (21), we obtain the following equation for $g_{a}$ :

$$
A^{\frac{1}{1-\gamma}} S^{-\frac{\gamma}{1-\gamma}}\left(g_{a}+B\right)^{\frac{\phi-\gamma}{1-\gamma}}=g_{a}+n
$$

Both hands are functions of $g_{a}$. Thus, we can rewrite them as follows:

$$
\begin{aligned}
& \mathrm{LHS} \equiv F_{g_{a}}\left(g_{a}\right)=A^{\frac{1}{1-\gamma}} S^{-\frac{\gamma}{1-\gamma}}\left(g_{a}+B\right)^{\frac{\phi-\gamma}{1-\gamma}}, \\
& \mathrm{RHS} \equiv G_{g_{a}}\left(g_{a}\right)=g_{a}+n .
\end{aligned}
$$

The intersection of these curves determines $g_{a}^{*}$. 
[Figures 10 and 11 to be inserted here]

\section{B Appendix 2}

We investigate the effects of changes in parameters on the long-run equilibrium. A parameter, $\Omega$, which will appear below, is defined as

$$
\Omega \equiv 1-\frac{(\phi-\gamma) s u}{1-\gamma}
$$

When $\phi<\gamma$, we have $\Omega>0$. When $\phi>\gamma, 0<(\phi-\gamma) /(1-\gamma)<1$ because $0<\phi<1$. Since $0<s<1$ and $0<u<1$, we have $\Omega>0$ when $\phi>\gamma$. Therefore, we always have $\Omega>0$ irrespective of $\phi<\gamma$ or $\phi>\gamma$.

Moreover, $B$ is defined as $B \equiv \theta m_{f}+(1-\theta) m_{w}$ as in the text. A rise in $\theta, m_{f}$, and $m_{w}$ leads to a rise in $B$ given $m_{f}>m_{w}$.

Finally, all endogenous variables are evaluated at the long-run equilibrium.

- The rate of capacity utilization

$$
\begin{aligned}
\frac{d u^{*}}{d s} & =-\frac{1}{1-\gamma} A^{\frac{1}{1-\gamma}} S^{\frac{\gamma-2}{1-\gamma}} m^{\frac{\phi-1}{1-\gamma}} \frac{1-\phi s u}{\Omega}<0, \\
\frac{d u^{*}}{d n} & =\frac{1-\phi}{1-\gamma} A^{\frac{1}{1-\gamma}} S^{-\frac{1}{1-\gamma}} m^{\frac{\phi+\gamma-2}{1-\gamma}} \frac{1}{\Omega}>0, \\
\frac{d u^{*}}{d B} & =-\frac{1-\phi}{1-\gamma} A^{\frac{1}{1-\gamma}} S^{-\frac{1}{1-\gamma}} m^{\frac{\phi+\gamma-2}{1-\gamma}} \frac{1}{\Omega}<0, \\
\frac{d u^{*}}{d A} & =\frac{1}{1-\gamma} s^{\frac{1}{1-\gamma}} A^{\frac{\gamma}{1-\gamma}} m^{\frac{\phi-1}{1-\gamma}} \frac{1-s u}{\Omega}>0 .
\end{aligned}
$$

- The profit share

$$
\begin{aligned}
\frac{d m^{*}}{d s} & =-\frac{\gamma}{1-\gamma} \text { mu } \frac{1}{\Omega}<0, \\
\frac{d m^{*}}{d n} & =-\frac{1}{\Omega}<0, \\
\frac{d m^{*}}{d B} & =\frac{1}{\Omega}>0, \\
\frac{d m^{*}}{d A} & =\frac{1}{1-\gamma} A^{-1} \text { smu } \frac{1}{\Omega}>0 .
\end{aligned}
$$

- The growth rate of labor productivity 
In the long-run equilibrium we have $g_{a}^{*}=m^{*}-B$. Hence, results for the parameters except $B$ are the same as in the case of $m^{*}$. As for $B$, we have

$$
\frac{d g_{a}^{*}}{d B}=\frac{\phi-\gamma}{1-\gamma} s u \frac{1}{\Omega}
$$

This derivative will be negative when $\phi<\gamma$ while positive when $\phi>\gamma$.

- The rate of capital accumulation

In the long-run equilibrium we have $g^{*}=g_{a}^{*}+n$. Hence, results for the parameters except $n$ are the same as in the case of $g_{a}^{*}$. The relationship between $g^{*}$ and $m^{*}$ is given by

$$
g^{*}=A^{\frac{1}{1-\gamma}} S^{-\frac{\gamma}{1-\gamma}}\left(m^{*}\right)^{\frac{\phi-\gamma}{1-\gamma}} .
$$

As shown above, an increase in $n$ leads to a decrease in $m^{*}$. Therefore, we have $d g^{*} / d n>0$ when $\phi<\gamma$ while $d g^{*} / d n<0$ when $\phi>\gamma$.

\section{References}

Bhaduri, A. and Marglin, S. 1990. Unemployment and the real wage: the economic basis for contesting political ideologies, Cambridge Journal of Economics, vol. 14, 375-93

Bhaduri, A. 2006. Endogenous economic growth: a new approach, Cambridge Journal of Economics, vol. 30, 69-83

Blecker, R. A. 2002. Distribution, demand and growth in neo-Kaleckian macro-models, in Setterfield, M. (ed.), The Economics of Demand-led Growth, Challenging the Supplyside Vision of the Long Run, Cheltenham, Edward Elgar

Cassetti, M. 2002. Conflict, inflation, distribution and terms of trade in the Kaleckian model, in Setterfield, M. (ed.), The Economics of Demand-led Growth, Challenging the Supply-side Vision of the Long Run, Cheltenham, Edward Elgar

Cassetti, M. 2003. Bargaining power, effective demand and technical progress: a Kaleckian model of growth, Cambridge Journal of Economics, vol. 27, 449-64

Cassetti, M. 2006. A note on the long-run behaviour of Kaleckian models, Review of Political Economy, vol. 18, 497-508

Dutt, A. K. and Amadeo, E. J. 1993. A post-Keynesian theory of growth, interest and money, in Baranzini, M. and Harcourt, G. C. (eds), The Dynamics of the Wealth of Nations: Growth, Distribution and Structural Change, New York, St.Martin's Press 
Dutt, A. K. 2006. Aggregate demand aggregate supply and economic growth, International Review of Applied Economics, vol. 20, 319-36

Foley, D. K. and Michl, T. R. 1999. Growth and Distribution, Cambridge, MA, Harvard University Press

Gandolfo, G. 1996. Economic Dynamics, 3rd edition, Berlin, Springer-Verlag

Kaldor, N. 1966. Causes of the slow rate of economic growth in the United Kingdom, reprinted in Kaldor, N. 1978. Further Essays on Economic Theory, London, Duckworth

Kalecki, M. 1954. Theory of Economics Dynamics, London, George Allen and Unwin

Kalecki, M. 1971. Selected Essays on the Dynamics of the Capitalist Economy, Cambridge, Cambridge University Press

Lavoie, M. 1992. Foundations of Post-Keynesian Economic Analysis, Cheltenham, Edward Elgar

Lavoie, M. 2006. Introduction to Post-Keynesian Economics, New York, Palgrave Macmillan

León-Ledesma, M. A. and Thirlwall, A. P. 2002. The endogeneity of the natural rate of growth, Cambridge Journal of Economics, vol. 26, 441-59

Libânio, G. A. 2009. Aggregate demand and the endogeneity of the natural rate of growth: evidence from Latin American economies, Cambridge Journal of Economics, doi:10.1093/cje/ben059

Lima, G. T. 2004. Endogenous technological innovation, capital accumulation and distributional dynamics, Metroeconomica, vol. 55, 386-408

Marglin, S. 1984. Growth, Distribution, and Prices, Cambridge, MA, Harvard University Press

Marglin, S. and Bhaduri, A. 1990. Profit squeeze and Keynesian theory, in Marglin, S. and Schor, J. (eds), The Golden Age of Capitalism: Reinterpreting the Postwar Experience, Oxford, Clarendon Press

Pasinetti, L. L. 1974. Growth and Income Distribution, Cambridge, Cambridge University Press

Rowthorn, R. E. 1977. Conflict, inflation and money, Cambridge Journal of Economics, vol. 1, 215-39

Rowthorn, R. E. 1981. Demand, real wages and economic growth, Thames Papers in Political Economy, Autumn, 1-39 
Rowthorn, R. E. 1999. Unemployment, wage bargaining and capital-labour substitution, Cambridge Journal of Economics, vol. 23, 413-25

Sedgley, N. and Elmslie, B. 2004. The conventional wage share vs. full employment: implications for the development of growth theory, Cambridge Journal of Economics, vol. $28,875-88$

Setterfield, M. 2009. Macroeconomics without the LM curve: an alternative view, Cambridge Journal of Economics, vol. 33, 273-93

Stockhammer, E. 2004. Is there an equilibrium rate of unemployment in the long run? Review of Political Economy, vol. 16, 59-77

Stockhammer, E. 2008. Is the NAIRU theory a Monetarist, New Keynesian, Post Keynesian or a Marxist theory? Metroeconomica, vol. 59, 479-510

Stockhammer, E. and Onaran, Ö. 2004. Accumulation, distribution and employment: a structural VAR approach to a Kaleckian macro model, Structural Change and Economic Dynamics, vol. 15, 421-47

Storm, S. and Naastepad, C. W. M. 2007. It is high time to ditch the NAIRU, Journal of Post Keynesian Economics, vol. 29, 531-54

Storm, S. and Naastepad, C. W. M. 2008. The NAIRU reconsidered: why labour market deregulation may rise unemployment, International Review of Applied Economics, vol. $22,527-44$.

Taylor, L. 2004. Reconstructing Macroeconomics: Structuralist Proposals and Critiques of the Mainstream, Cambridge, MA, Harvard University Press.

Verdoorn, P. J. 1949. Fattori che regolano lo sviluppo della produttività del lavoro, L'Industria, vol. 1, 14-28 (Factors that determine the growth of labour productivity, translated by Thirlwall, A. P. in McCombie, J., Pugno, M. and Soro, B. (eds), Productivity Growth and Economic Performance: Essays on Verdoorn's Law, London, Macmillan, 2002)

Vogel, L. 2009. The endogeneity of the natural rate of growth-an empirical study for Latin-American countries, International Review of Applied Economics, vol. 23 41-53

You, J-I. 1994. Macroeconomic structure, endogenous technical change and growth, Cambridge Journal of Economics, vol. 18, 213-33 


\section{Figures and Tables}

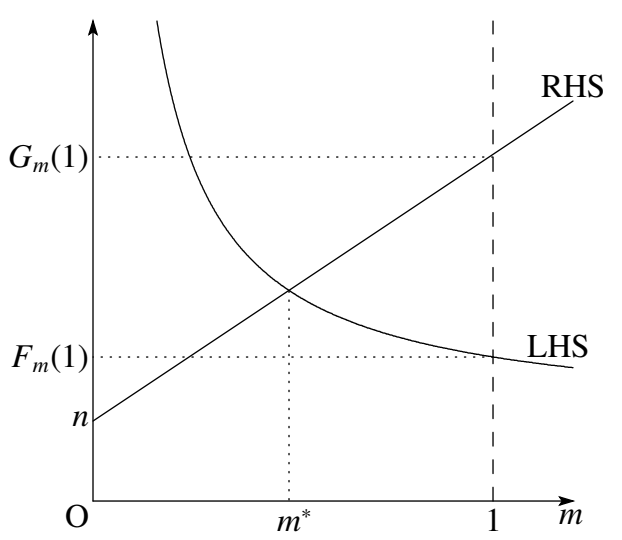

Figure 1: Determination of $m^{*}(\phi<\gamma)$

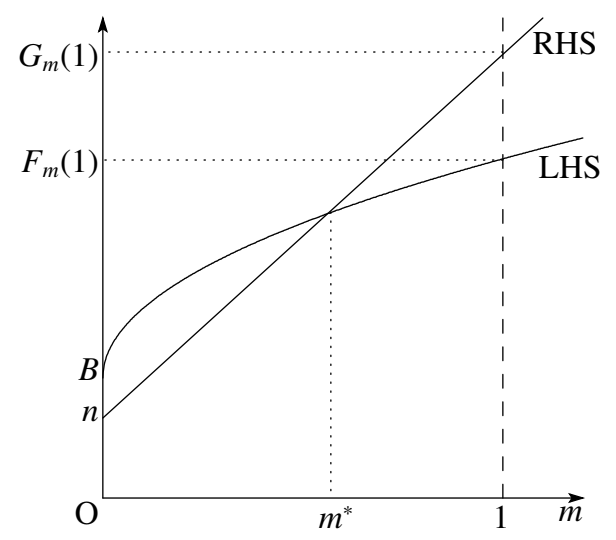

Figure 2: Determination of $m^{*}(\phi>\gamma)$
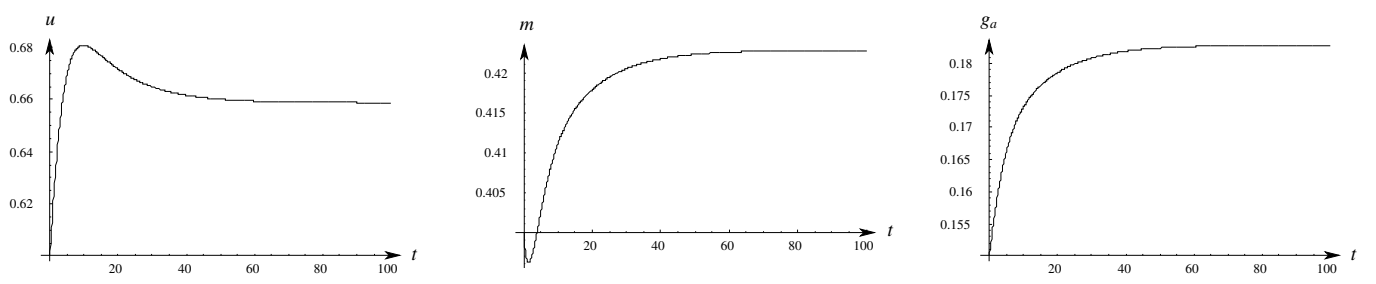

Figure 3: Time path of $u$ Figure 4: Time path of $m$ Figure 5: Time path of $g_{a}$ $(\phi<\gamma)$

$$
(\phi<\gamma)
$$

$(\phi<\gamma)$
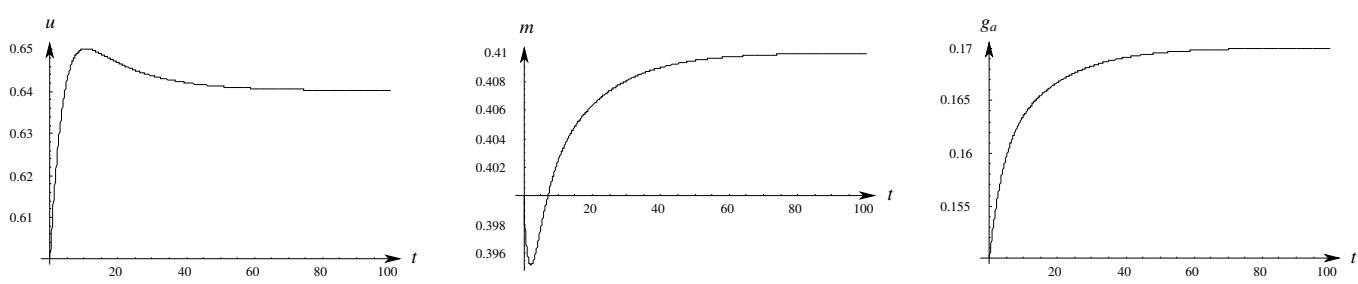

Figure 6: Time path of $u$ Figure 7: Time path of $m$ Figure 8: Time path of $g_{a}$ $(\phi>\gamma)$ $(\phi>\gamma)$ $(\phi>\gamma)$ 
Table 1: Equilibrium values for Cases 1 and 2

\begin{tabular}{cccc}
\hline & $u^{*}$ & $m^{*}$ & $g_{a}^{*}$ \\
\hline Case 1 & 0.66 & 0.42 & 0.18 \\
Case 2 & 0.64 & 0.41 & 0.17 \\
\hline
\end{tabular}

Table 2: Results for comparative statics analysis

\begin{tabular}{rccccc}
\hline & $s$ & $n$ & $\theta^{\dagger}$ & $m_{f}, m_{w}^{\dagger}$ & $A$ \\
\hline$u^{*}$ & - & + & - & - & + \\
$m^{*}$ & - & - & + & + & + \\
$g_{a}^{*}, e^{*}$ & - & - & $-/+^{\ddagger}$ & $-/+^{\ddagger}$ & + \\
$g^{*}$ & - & $+/--^{\ddagger}$ & $-/+^{\ddagger}$ & $-/+^{\ddagger}$ & + \\
\hline
\end{tabular}

$\dagger$ We assume $m_{f}>m_{w}$.

When $\phi<\gamma$, the left-hand sign applies, and when $\phi>\gamma$, the right-hand sign applies.

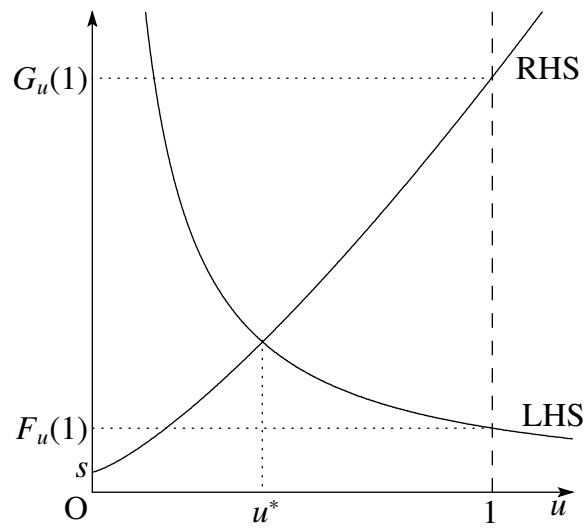

Figure 9: Determination of $u^{*}$ 


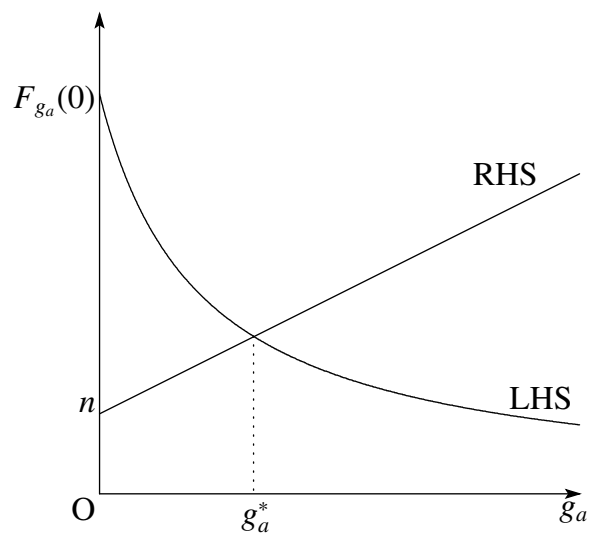

Figure 10: Determination of $g_{a}^{*}(\phi<\gamma)$

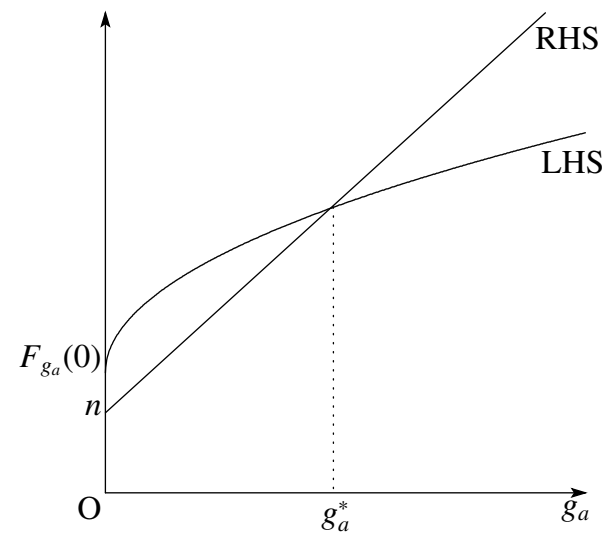

Figure 11: Determination of $g_{a}^{*}(\phi>\gamma)$ 